\title{
Review \\ Health technology assessment review: Computerized glucose regulation in the intensive care unit - how to create artificial control
}

\author{
Miriam Hoekstra ${ }^{1}$, Mathijs Vogelzang ${ }^{2,3}$, Evgeny Verbitskiy ${ }^{4,5}$ and Maarten WN Nijsten ${ }^{6}$ \\ ${ }^{1}$ Departments of Anesthesiology and Cardiology, University Medical Center Groningen, 9700 RB Groningen, the Netherlands \\ ${ }^{2}$ Department of Cardiology, University Medical Center Groningen, 9700 RB Groningen, the Netherlands \\ ${ }^{3} \mathrm{Google}, \mathrm{CH}-8002$ Zurich, Switzerland \\ ${ }^{4}$ Department of Dynamical Systems and Mathematical Physics, Research Institute for Mathematics and Computing Science, University of Groningen, \\ 9700 AK Groningen, the Netherlands \\ 5 Information and System Security, Philips Research, 5621 BA Eindhoven, the Netherlands \\ ${ }^{6}$ Department of Intensive Care, University Medical Center Groningen, 9700 RB Groningen, the Netherlands
}

Corresponding author: Miriam Hoekstra, m.hoekstra@thorax.umcg.nl

Published: 16 October 2009

This article is online at http://ccforum.com/content/13/5/223

(c) 2009 BioMed Central Ltd
Critical Care 2009, 13:223 (doi:10.1186/cc8023)

\begin{abstract}
Current care guidelines recommend glucose control (GC) in critically ill patients. To achieve GC, many ICUs have implemented a (nurse-based) protocol on paper. However, such protocols are often complex, time-consuming, and can cause iatrogenic hypoglycaemia. Computerized glucose regulation protocols may improve patient safety, efficiency, and nurse compliance. Such computerized clinical decision support systems (CDSSs) use more complex logic to provide an insulin infusion rate based on previous blood glucose levels and other parameters. A computerized CDSS for glucose control has the potential to reduce overall workload, reduce the chance of human cognitive failure, and improve glucose control. Several computer-assisted glucose regulation programs have been published recently. In order of increasing complexity, the three main types of algorithms used are computerized flowcharts, ProportionalIntegral-Derivative (PID), and Model Predictive Control (MPC). PID is essentially a closed-loop feedback system, whereas MPC models the behaviour of glucose and insulin in ICU patients. Although the best approach has not yet been determined, it should be noted that PID controllers are generally thought to be more robust than MPC systems. The computerized CDSSs that are most likely to emerge are those that are fully a part of the routine workflow, use patientspecific characteristics and apply variable sampling intervals.
\end{abstract}

\section{Introduction}

There is widespread consensus [1] that hyperglycaemia should be treated with insulin in patients in the ICU, although appropriate glucose levels achieved through glucose control (GC) are still under debate. Insulin therapy in ICU patients, even with a moderate glucose target range, is complex and time consuming, particularly since insulin-induced severe hypoglycaemia should be avoided. In most ICUs, protocols for GC are paper-based and nurse-driven. However, even with this form of standardization medication errors frequently occur and play a major part in overall patient safety, which is a key issue in all healthcare systems. For safety and efficiency, computerized clinical decision support systems (CDSSs) appear to be superior to standard paper protocols. Patient data management systems and computerized physician order entries are increasingly being used in the ICU, both with and without decision support. This review focuses on the progressively more complex approaches that have recently been introduced to achieve GC. Successful implementation of computer-guided GC is of relevance to other ICU domains, since the basic titration principle behind GC (for example, increase insulin infusion if glucose is high) holds for numerous other clinical ICU problems. Although this is not a formal exhaustive review, this paper discusses several important studies on paper protocols and development of computer assisted methods, including flowcharts, Proportional-Integral-Derivative (PID) and Model Predictive Controllers (MPC).

\section{Glucose control with paper protocols}

Hyperglycaemia frequently occurs in critically ill patients and is strongly associated with adverse outcome in patients with acute myocardial infarction [2], stroke [3], and trauma [4,5]. Also in a heterogeneous ICU population hyperglycaemia was associated with increased hospital mortality [6,7]. This observation raised the interesting question of whether normalizing blood glucose (BG) improves outcome. In 2001 van den Berghe and colleagues [8] showed a one-third mortality reduction in surgical ICU patients treated with

$\mathrm{BG}=$ blood glucose; CDSS = clinical decision support system; CGMS = continuous glucose monitoring system; GC = glucose control; MPC = Model Predictive Control; PID = Proportional-Integral-Derivative. 
intensive insulin therapy (using a paper protocol for insulin infusion). However, subsequent high-quality controlled trials [9-11] and a large cohort study [12] in both medical and surgical ICU patients could not replicate this mortality benefit. The recently published international NICE-SUGAR (Normoglycaemia in Intensive Care Evaluation - Survival Using Algorithm Regulation) trial [13] demonstrated in 6,104 patients that 'tight' GC with a target of 4.5 to $6.0 \mathrm{mmol} / \mathrm{L}$ was associated with a higher mortality. The investigators used a computer-assisted glucose regulation protocol. In the metaanalysis that followed (including the NICE-SUGAR study data), no mortality benefit was demonstrated in the tight glycemic control group [14]. However, because there is consensus about avoiding serious hyperglycaemia, GC in ICU patients is still recommended so that glucose levels should be kept at approximately $<8.0 \mathrm{mmol} / \mathrm{L}[1,13]$.

To achieve desired glucose levels, insulin therapy is required in most ICU patients. GC requires intensive monitoring of glucose levels with frequent adjustments of insulin therapy. A first step in managing $\mathrm{GC}$ is the use of protocols that allow physicians and nurses to decide unambiguously how much insulin should be administered. The recommendations of these protocols are generally based on previous glucose levels and insulin dosing according to a 'sliding scale' protocol (a predetermined amount of insulin is administered according to the actual BG) or 'dynamic' protocol (the dosage of insulin is changed by a certain amount, according to the actual BG) [15]. Given the frequency of BG sampling, it rapidly became apparent that the nurses who care for the patient should have a central role in executing GC. Standardizing GC by a nurse-managed protocol has been found to improve safety and efficiency of GC [16].

\section{Hypoglycaemia}

One of the main challenges in achieving glycaemic control is minimizing the risk of hypoglycaemia. Hypoglycaemia can cause serious complications and should be prevented in critically ill patients [17]. In several studies an increased occurrence of severe hypoglycaemia was strongly associated with tight glycemic control. Two large trials investigating the clinical effects of strict GC that were prematurely ended showed high rates of iatrogenic hypoglycaemia $[10,11]$. Although the overall evidence suggests that the beneficial effects of insulin therapy may outweigh the possible negative effects of hypoglycaemia [18], fatalities occurring due to iatrogenic hypoglycaemia are not acceptable. A balance must be struck between the preferred level of control and the number of measurements. To achieve GC with a low incidence of hypoglycaemia without excessive BG sampling, more complex computer supported algorithms are required that manage the patients with an increased risk for hypoglycemia.

\section{Introduction of computerized glucose control}

For many years, computer software has been recognized as a promising tool to improve clinical practice as many adverse events can be traced back to preventable human errors. These so-called CDSSs are information systems designed to improve clinical decision making using characteristics of the individual patient. Implementations of these systems have been shown to reduce serious medication errors [19] and improve adherence to recommended care [20]. In the past few years several computer directed glucose regulation programs have been investigated for their effectiveness and safety in critically ill patients. We performed a literature search (PubMed, Cochrane and Medline) to find published computer-based intravenous insulin protocols that were designed for critically ill patients and tested in an ICU setting (in at least 15 patients). Table 1 summarizes the 19 identified studies [13,21-38].

\section{How to create artificial control?}

Devising an algorithm for controlling blood glucose is a challenging task. The algorithm should be evaluated to be safe, robust and efficient for a population of patients with a wide range of clinical conditions. To date, three types of algorithms have been considered for BG regulation: (heuristic) paper-based or equivalent computerized flowcharts, PID and MPC.

\section{Computerized flowcharts}

The first flow-chart protocol was based on studies by van den Berghe and colleagues $[8,9]$. It allows nurses to determine (at the bedside) the necessary adjustment of the insulin pump based on the most recent $B G$ value and the trend (using the number and levels of past BG values to determine the trend). In case of extremely low BG or other exceptional cases, special actions are planned. The paper-based flow-chart protocol can easily be converted into a computerized form (see, for example, Thomas and colleagues [36] and Laha and colleagues [28]). Furthermore, the use of computers allows an increase in the sensitivity (resolution) of the titration part, for example, in the Vanderbilt protocol [21]. The formula uses a simple multiplier, which is determined and adjusted according to previous BGs (BG in mmol/L; multiply multiplier by 18 for $B G$ in $\mathrm{mg} / \mathrm{dl})$ :

$$
\text { Insulin dose }(\mathrm{U} / \mathrm{h})=\text { Multiplier } \times(\mathrm{BG}-3.3)(\text { Equation 1) }
$$

where the multiplier is adjusted by 0.01 up or down when two consecutive BGs are above 6.1 or below $4.4 \mathrm{mmol} / \mathrm{L}$, respectively; in the case of extreme values ( $<3.3$ or $>11 \mathrm{mmol} / \mathrm{L}$ ) the multiplier is adjusted by 0.02 , and in the case of $B G<3.3$, the insulin dose becomes zero. Boord and colleagues [21], and later Dortch and colleagues [24], demonstrated an improvement in overall GC compared to a previous manual protocol. At the same time, a glucose sample was required approximately 18 times per day.

\section{PID control}

A titration formula like Equation 1 puts the control algorithm in the class of the so-called PID controllers. These are the most 


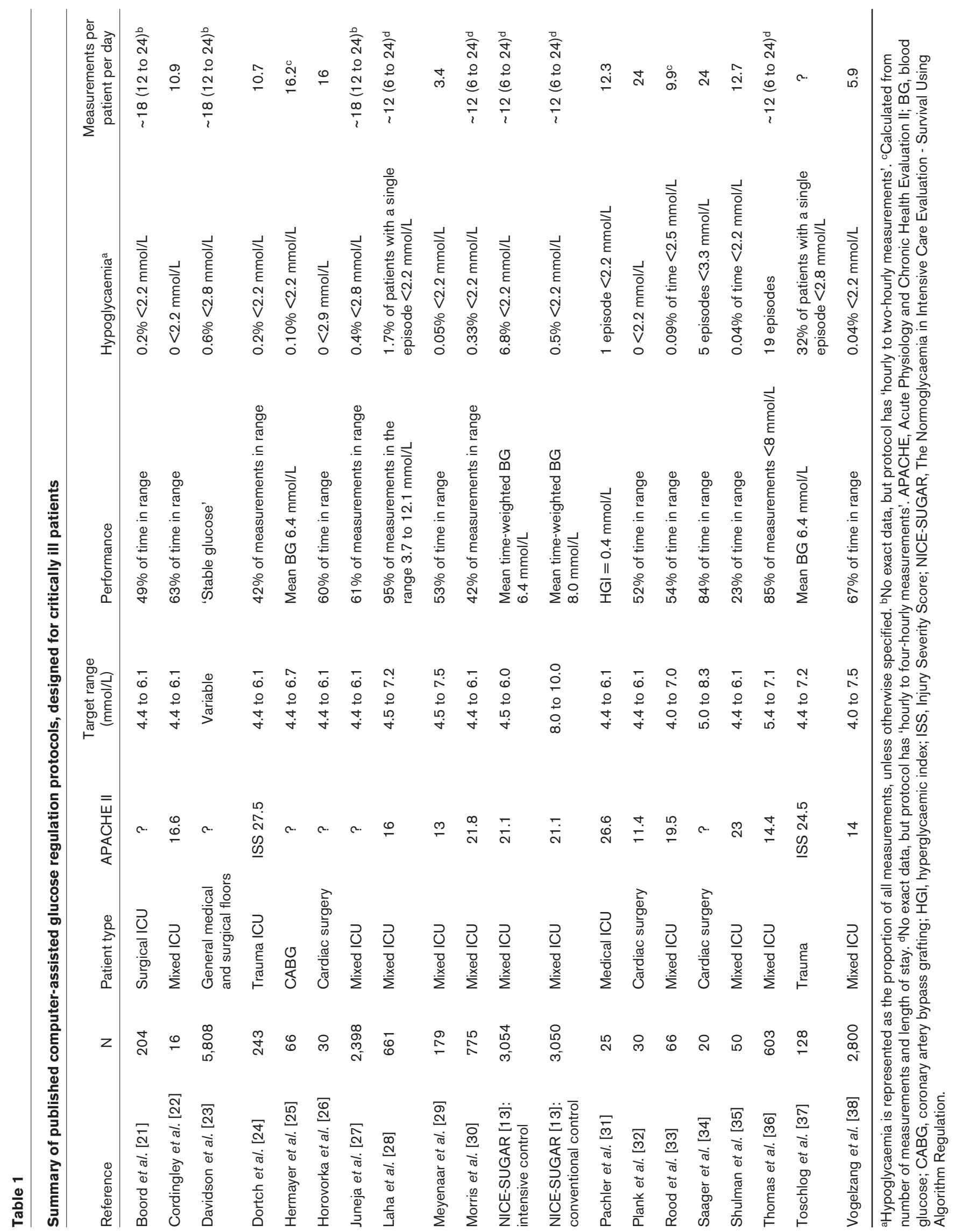


widely used controllers in industrial applications. Typical examples are the kitchen furnace and automotive cruise control. The basic idea of PID control is easy to explain: deviation of the controlled quantity ( $B G$ in our case) from the target is corrected by adapting the control parameter (insulin) using a linear combination of absolute deviation, trend, and the sum of past deviations. In fact, a PID controller has already been used in the BioStator, the first device for 'glucose clamping', developed in the late 1970s [39]. Equation 1 utilizes only the proportional (P) part of the PID control. Vogelzang and colleagues $[38,40]$ also use the derivative (D) component. For the rationale behind the application of the integral (I) part, see Wintergerst and colleagues [41].

\section{Model predictive controllers}

A great deal of work has been invested in mathematical modelling of glucose regulation. Models of various complexities have been constructed in the past 50 years, as recently comprehensively reviewed by Chee and Fernando [42]. Deterministic mathematical models can also serve as a basis for the development of control algorithms. Given the model equations and the values of all model parameters, one is able, in principle, to precisely compute the glucose evolution in response to any insulin infusion strategy. In theory, this allows a selection of an optimal insulin infusion scenario. In practice, however, mathematical models rarely exactly describe reality, and a large number of parameters need to be estimated, which will inevitably lead to errors in prediction of glucose response.

An example of such complex MPC was developed by the CLINICIP (Closed Loop Insulin Infusion in Critically III Patients) group. The ultimate goal is a closed loop system for glycemic control. Plank and colleagues [32] describe, in a multicenter randomized controlled trial, glucose management with the MPC program in 30 patients after cardiac surgery. Compared with routine protocols for glucose regulation, the time within target range improved significantly (19\% to $52 \%$ ) during the first 24 hours postoperatively. However, an hourly glucose sample was necessary, which substantially increased the workload of the ICU nursing staff. Thereafter, the algorithm was enhanced with a variable sampling interval based on the accuracy of the glucose prediction. The improved protocol (eMPC) resulted in a 50\% drop in sampling frequency [31] and maintained effective glucose control in different ICUs, with different (nutritional) protocols and during cardiac surgery $[22,26]$. The authors report that the program was safe in 30 patients. It should be noted, however, that the published incidence of hypoglycaemia, a key safety indicator, varies from less than $1 \%$ to a few percent, thus rendering a sample size too small to assess such a safety parameter.

\section{PID versus MPC}

The following might serve as a caricature explanation of the difference between PID and MPC. Suppose a person wants to drive a car on a mountain road. The control (equivalent to
Figure 1

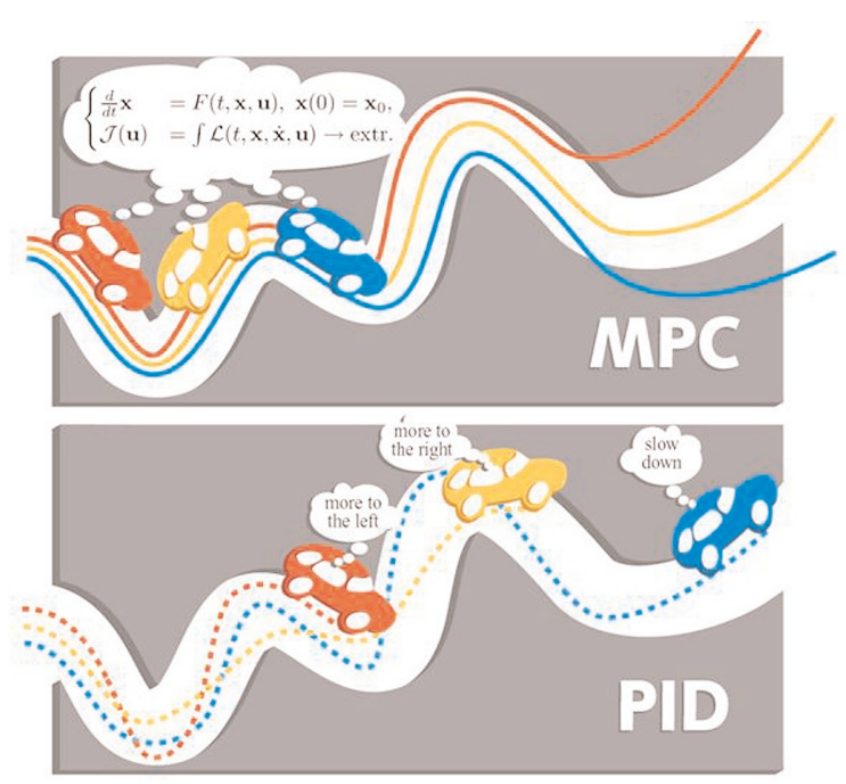

Model Predictive Control (MPC) versus Proportional-IntegrateDerivative (PID) control. When using MPC control, the driver determines ('calculates') his driving strategy before departure after careful investigation of the road. When he uses the correct information (input variables), he stays on the road (yellow car), but small errors in input variables can lead the car in the wrong direction (red and blue cars). The drivers using PID control readjust their driving strategy often by frequently calculating the difference with the 'ideal' track.

the art of driving) consists of two continuous inputs: steering and throttle. The PID approach would be analogous to a driver negotiating the road by continuously adjusting the input parameters, correcting deviation from the ideal line, proceeding along as the new corners or obstacles appear in front. The MPC strategy would be analogous to studying the whole road and selecting the driving strategy before the departure. Note that even the MPC approach does not guarantee $100 \%$ success as the strategy might have to be adjusted to changing conditions like rain, other road users, and so on. This example is illustrated in Figure 1.

The theoretical advantage of the MPC over the PID approach is that the 'intelligent' control algorithm could be able to minimize glucose oscillations and keep glucose within the target range better than PID controllers. This, however, would require further improvement of not only the mathematical models and the parameter estimation procedures, but the control algorithms as well, since the current results of in silico (that is, with a virtual electronic patient) testing exhibit rather dramatic oscillatory behavior [43].

Finally, some believe that with the envisioned introduction of continuous glucose monitoring systems (CGMSs) in the ICU setting, the current problem - high workload for nurses 
resulting from frequent glucose measurements - will reduce considerably. Results reported in the literature strongly suggest that, with the frequent sampling of $B G$, the more transparent PID controllers are fully capable of regulating glucose successfully. However, application of CGMSs in the ICU setting is still hampered by a relative inaccuracy of the existing sensors. Moreover, it must be noted that regardless of the algorithm employed, CGMSs may not come so easily or cheaply as originally envisioned, since the devices are expensive and may require quite frequent $B G$ samples as well, albeit only for calibration purposes. For more discussion on the combination of CGMSs and PID controllers or PID control versus MPC control see [44-48].

\section{Computer versus paper-based insulin infusion protocols}

Whether computer-based or paper-based, the underlying algorithm is the crucial 'know-how' responsible for overall performance. The same algorithm in paper or computer form should have the same overall performance, provided that nurses are easily able to use both versions and comply with recommendations in the same way. Computer implementations probably offer higher comfort to the nursing staff. The chance of human error grows dramatically with the complexity of the protocol when it is implemented on paper. Therefore, the class of all protocols potentially implementable by humans is strictly smaller than the class of protocols implementable on the computer.

\section{Successful implementation of decision support systems}

To make the implementation of a computerized CDSS successful, the algorithm used is not the only element that must be taken into account. Kawamoto [49] performed a systematic review to identify features critical to the success of a CDSS and concluded that to make a program likely to succeed, it must be fully part of the caregivers' routine workflow and provide the decision support at the time and location of the actual decision making. Also transparency, such as documentation of the reasons behind the decision making, and a feedback mechanism (for example, an alarm as a reminder for when a glucose sample is required) were features leading to success. Before implementation, adequate training of the nursing staff and physicians is important. To date, no systematic studies on the costs of computerized protocols have been published, but it is likely that a program that requires 18 measurements per day will turn out to be more expensive than one that requires 6 measurements per day.

\section{Future perspectives}

To improve patient safety, more and more technology will arise in healthcare, especially in the ICU, where the complexity of patient care is high. A system that is effective, safe, transparent and easy to work with has a chance to become routine practice. An advantage of computerized regulation is that improvements of the internal algorithm may enable a higher level of control and safety while maintaining a simple user interface. To date there have been no direct comparisons made between different algorithms, so the best approach has not been determined yet. Development of a closed-loop system using continuous BG measurements has been ongoing for many years. For the near future, the method of choice for insulin therapy will still be based on intermittent glucose sampling because the continuous techniques are not yet reliable enough (mainly in the hypoglycaemic area) and are expensive.

\section{Conclusion}

Computer-assisted glycemic control has proven to be more safe and effective than paper protocols in ICU patients. A successful system is nurse-centered, fully integrated into the routine workflow, transparent, and uses patient-specific information with intermittent glucose measurements and variant sampling intervals.

\section{Competing interests}

The work of EV on glucose regulation in the ICU is supported by the Netherlands Science Organization through the national cluster 'Non-linear dynamics of natural systems'. $\mathrm{MH}$, $\mathrm{MV}$ and $\mathrm{MN}$ declare that they have no competing interests.

\section{Acknowledgements}

The authors would like to acknowledge Felix Zijlstra and Iwan van der Horst for critical reading of the manuscript.

\section{References}

1. Dellinger RP, Levy MM, Carlet JM, Bion J, Parker MM, Jaeschke R, Reinhart K, Angus DC, Brun-Buisson C, Beale R, Calandra T, Dhainaut JF, Gerlach H, Harvey M, Marini JJ, Marshall J, Ranieri M, Ramsay G, Sevransky J, Thompson BT, Townsend S, Vender JS, Zimmerman JL, Vincent JL: Surviving sepsis campaign: international guideliness for management of severe sepsis and septic shock. Intensive Care Med 2008, 34:17-60.

2. Capes SE, Hunt D, Malmberg K, Gerstein HC: Stress hyperglycemia and increased risk of death after myocardial infarction in patients with and without diabetes: a systematic overview. Lancet 2000, 355:773-778.

3. Capes SE, Hunt D, Malmberg K, Pathak P, Gerstein HC: Stress hyperglycemia and prognosis of stroke in nondiabetic and diabetic patients: a systematic overview. Stroke 2001, 32: 2426-2432.

4. Wahl WL, Taddonio M, Maggio PM, Arbabi S, Hemmila MR: Mean glucose values predict trauma patient mortality. J Trauma 2008, 65:42-47.

5. Lipshultz AK, Gropper MA: Peri-operative glycemic control: an evidence based review. Anesthesiology 2009, 110:408-421.

6. Krinsley JS: Association between hyperglycemia and increased hospital mortality in a heterogeneous population of critically ill patients. Mayo Clin Proc 2003, 78:1471-1478.

7. Vogelzang M, Nijboer JM, van der Horst IC, Zijlstra F, ten Duis HJ, Nijsten MW: Hyperglycemia has a stronger relation with outcome in trauma patients than in other critically ill patients. J Trauma 2006, 60:873-877.

8. van den Berghe G, Wouters P, Weekers F, Verwaest C, Bruyninckx F, Schetz M, Vlasselaers D, Ferdinande P, Lauwers P, Bouillon R: Intensive insulin therapy in the critically ill patients. $N$ Engl J Med 2001, 345:1359-1367.

9. Van den Berghe G, Wilmers A, Hermans G, Meersseman W, Wouters PJ, Milants I, Van Wijngaerden E, Bobbaers H, Bouillon $\mathrm{R}$ : Intensive insulin therapy in the medical ICU. N Engl J Med 2006, 354:449-461. 
10. Brunkhorst FM, Engel $C$, Bloos F, Meier-Hellmann A, Ragaller $M$, Weiler N, Moerer O, Gruendling M, Oppert M, Grond S, Olthoff D, Jaschinski U, John S, Rossaint R, Welte T, Schaefer M, Kern P, Kuhnt E, Kiehntopf M, Hartog C, Natanson C, Loeffler M, Reinhart $\mathrm{K}$ : Intensive insulin therapy and pentastarch resuscitation in severe sepsis. N Engl J Med 2008, 358:125-139.

11. Devos $P$, Preiser JC, Mélot C: Impact of tight glucose control by intensive insulin therapy on ICU mortality and the rate of hypoglycaemia: final results of the Glucontrol study. Intensive Care Med 2007; 33(Suppl 2):S189.

12. Treggiari MM, Karir V, Yanez ND, Weiss NS, Daniel S, Deem SA: Intensive insulin therapy and mortality in critically ill patients. Crit Care 2008, 12:R29.

13. The NICE-SUGAR study investigators: Intensive versus conventional glucose control in critically ill patients. N Eng J Med 2009, 360:1283-1297.

14. Griesdale DEG, deSouza RJ, van Dam RM, Heyland DK, Cook DJ, Malhotra A, Dhaliwal R, Henderson WR, Chittock DR, Finfer S, Talmor D: Insulin therapy and mortality among critically ill patients: a meta-analysis including NICE-SUGAR study data. CMAJ 2009, 180:821-827.

15. Meijering S, Corstjens AM, Tulleken JE, Meertens JM, Zijlstra JG, Ligtenberg JM: Towards a feasible algorithm for tight glycaemic control in critically ill patients: a systematic review of the literature. Crit Care 2006, 10:R19.

16. Kanji S, Singh A, Tierney M, Meggison H, Mclntyre L, Hebert PC: Standardization of intravenous insulin therapy improves the efficiency and safety of blood glucose control in critically ill adults. Intensive Care Med 2004, 30:804-810.

17. Krinsley JS, Grover A: Severe hypoglycaemia in critically ill patients: Risk factors and outcomes. Crit Care Med 2007, 35: 2262-2267.

18. Vriesendorp TM, de Vries JH, Hoekstra JB: Hypoglycemia and strict glycemic control in critically ill patients. Curr Opin Crit Care 2008, 14:397-402

19. Kaushal R, Shojania KG, bates DW: Effects of computerized physician order entry and clinical decision support systems on medication safety: a systematic review. Arch Intern Med 2003, 163:1409-1416.

20. Hunt DL, Haynes RB, Hanna SE, Smith K: Effects of computerbased clinical decision support systems on physician performance and patient outcomes: a systematic review. JAMA 1998, 280:1339-1346.

21. Boord JB, Sharifi M, Greevy RA, Griffin MR, Lee VK, Webb TA, May ME, Waitman LR, May AK, Miller RA: Computer-based insulin infusion protocol improves glycaemic control over manual protocol. J Am Med Inform Assoc 2007, 14:278-287.

22. Cordingley JJ, Vlasselaers D, Dormand NC, Wouters PJ, Squire SD, Chassin LJ, Wilinska ME, Morgan CJ, Hovorka R, Van den Berghe G: Intensive insulin therapy: enhanced model predicitive control algorithm versus standard care. Intensive Care Med 2009, 34:123-128.

23. Davidson PC, Steed RD, Bode BW: Glucommander: a computer-directed intravenous insulin system shown to be safe, simple and effective in $120,618 \mathrm{~h}$ of operation. Diabetes Care 2005, 28:2418-2423.

24. Dortch MJ, Mowery NT, Ozdas A, Dossett L, Cao H, Collier B, Holder G, Miller RA, May AK: A computerized insulin infusion titration protocol improves glucose control with less hypoglycemia compared to a manual titration protocol in a trauma intensive care unit. J Parenter Enteral Nutr 2008, 32:18-27.

25. Hermayer KL, Neal DE, Hushion TV, Irving MG, Arnold PC, Kozlowski L, Stroud MR, Kerr FB, Kratz JM: Outcomes of a cardiothoracic intensive care web-based online intravenous insulin infusion calculator study at a medical university hospital. Diabetes Technol Ther 2007, 9:523-534.

26. Horovorka R, Kremen J, Blaha J, Matias M, Anderlova K, Bosanska L, Roubicek T, Wilinska ME, Chassin LJ, Svacina S, Haluzik M: Blood glucose control by a model predictive control algorithm with variable sampling rate versus a routine glucose management protocol in cardiac surgery patients: a randomized controlled trial. J Clin Endocrinol Metab 2007, 92:2960-2964.

27. Juneja R, Roudebush C, Kumar N, Macy A, Golas A, Wall D, Wolverton C, Nelson D, Carroll J, Flanders SJ: Utilization of a computerized intravenous insulin infusion program to control blood glucose in the intensive care unit. Diabetes Technol Ther 2007, 9:232-240.
28. Laha SK, Taylor R, Collin SA, Ogden M, Thomas AN: Glucose control in critical illness using a web-based insulin dose calculator. Med Eng Phys 2008, 30:478-482.

29. Meyenaar IA, Dawson L, Tangkau PL, Salm EF, Rijks L: Introduction and evaluation of a computerized insulin protocol. Intensive Care Med 2007, 33:591-596.

30. Morris AH, Orme J, Truwit JD, Steingrub J, Grissom C, Lee KH, Li GL, Thompson BT, Brower R, Tidswell M, Bernard GR, Sorenson $D$, Sward K, Zheng $H$, Schoenfeld D, Warner $\mathrm{H}$ : A replicable method for blood glucose control in critically ill patients. Crit Care Med 2008, 36:1787-1795.

31. Pachler C, Plank J, Weinhandl H, Chassin LJ, Wilinska ME, Kulnik $\mathrm{R}$, Kaufmann P, Smolle KH, Pilger E, Pieber TR, Ellmerer M, Hovorka R: Tight glycaemic control by an automated algorithm with time-variant sampling in medical ICU patients. Intensive Care Med 2008, 34:1224-1230.

32. Plank J, Blaha J, Cordingley J, Wilinska ME, Chassin LJ, Morgan C, Squire S, Haluzik M, Kremen J, Svacina S, Toller W, Plasnik A, Ellmerer M, Hovorka R, Pieber TR: Multicenter, randomized, controlled trial to evaluate blood glucose by the model predictive control algorithm versus routine glucose management protocols in intensive care unit patients. Diabetes Care 2006, 29:271-276.

33. Rood E, Bosman RJ, van der Spoel JI, Taylor P, Zandstra DF: Use of computerized guideline for glucose regulation in the intensive care unit improved both guideline adherence and glucose regulation. J Am Med Inform Assoc, 12:172-180.

34. Saager L, Collins GL, Burnside B, Tymkew H, Zhang L, Jacobsohn $E$, Avidan $M$ : A randomized study in diabetic patients undergoing cardiac surgery comparing computer-guided glucose managment with a standard slinding scale protocol. $J$ Cardiothorac Vasc Anesth 2008, 22:377-382.

35. Shulman R, Finney S, O'Sullivan C, Glynne PA, Greene R: Tight glycaemic control: a prospective observational study of a computerized decision-supported intensive insulin therapy protocol. Crit Care 2007, 11:R75.

36. Thomas AN, Marchant AE, Ogden MC, Collin S: Implementation of a tight glycaemic control protocol using a web-based insulin dose calculator. Anaesthesia 2005, 60:1093-1100.

37. Toschlog EA, Newton C, Allen N, Newell MA, Goettler CE, Schenarts PJ, Bard MR, Sagraves SG, Rotondo MF: Morbidity reduction in critically ill trauma patients through use of a computerized insulin infusion protocol: a preliminary study. J Trauma 2007, 62:1370-1375.

38. Vogelzang M, Loef BG, Regtien JG, van der Horst IC, van Assen $\mathrm{H}$, Zijlstra F, Nijsten MWN: Computer-assisted glucose control in critically ill patients. Intensive Care Med 2008, 34:14211427.

39. Clemens $\mathrm{AH}$, Hough DL, D'Orazlo PA: Development of the Biostator Glucose clamping algorithm. Clin Chem 1982, 28: 1899-1904.

40. Vogelzang M, Zijlstra F, Nijsten MWN: Design and implementation of GRIP: a computerized glucose control system at a surgical intensive care unit. BMC Med Inform Decis Mak 2005, 5: 38.

41. Wintergerst KA, Deiss D, Buckingham B, Cantwell M, Kache S, Agarwal S, Wilson DM, Steil G: Glucose control in pediatric intensive care unit patients using an insulin-glucose algorithm. Diabetes Technol Ther 2007, 9:211-222.

42. Chee F, Fernando T: Closed-Loop Control of Blood Glucose, Lecture Notes in Control and Information Sciences. New York: Springer; 2007.

43. Wilinska ME, Chassin L, Hovorka R: In silico testing - impact on the progress of the closed loop insulin infusion for critically ill patients project. J Diabetes Sci Techno/ 2008, 2:417-423.

44. Steil GM, Deiss D, Shih J, Buckingham B, Weinzimer S, Agus MSD: Intensive care unit insulin delivery algorithms: Why so many? How to choose? J Diabetes Sci Technol 2009, 3:125140.

45. Weinzimer SA, Steil GM, Swan KL, Dziura J, Kurtz N, Tamborlane WV: Fully automated closed loop insulin delivery versus semi automated hybrid control in pediatric patients with type 1 diabetes using an artificial pancreas. Diabetes Care 2008, 31 : 934-939.

46. Marchetti G, Barolo M, Jovanovic L, Zisser H, Seborg DE: A feedforward-feedback glucose control strategy for type 1 diabetes mellitus. J Process Contro/ 2008, 18:149-162. 
47. Klonoff, DC: The artificial pancreas: how sweet engineering will solve bitter problems. J Diabetes Sci Techno/ 2007, 1:7281.

48. Bequette BW: A critical assessment of algorithms and challenges in the development of a closed-loop artificial pancreas. Diabetes Technol Ther 2005, 7:28-47.

49. Kawamoto K, Houlihan CA, Balas EA, Lobach DF: Improving clinical practice using clinical decision support systems: a systematic review of trials to identify features critical to success. BMJ 2005, 330:765. 